of a free radical. The dependence of the resonance absorption on temperature was similar to that of Wurster's radical ion, $\left(\mathrm{CH}_{3}\right)_{2} \mathrm{~N} \cdot\left(\mathrm{C}_{6} \mathrm{H}_{4}\right) \cdot \mathrm{N}\left(\mathrm{CH}_{3}\right)_{2}{ }^{+}$, the intensity of the absorption rising to a maximum near $200^{\circ} \mathrm{K} .4$.

Films of pure 'Perspex' showed no paramagnetic resonance after illumination with ultra-violet light.

The experiment was repeated with a solution of $p$-phenylenediamine, $\mathrm{NH}_{2} \cdot \mathrm{C}_{6} \mathrm{H}_{4} \cdot \mathrm{NH}_{2}$, which also forms free radical ions by photo-oxidation, though less easily than Wurster's base. After $25 \mathrm{~min}$. illumination, the film became coloured, brown at the edges and grey-green in the centro. Paramagnetic resonance showed that free radicals were present in the film, the concentration being greater in the grey-green part.

The radicals produced in this manner are rather stable. Paramagnetic resonance of about the original intensity was found after the illuminated film had been kept for a month at room temperature. After ten months, however, paramagnetic resonance could not be detected, although the film remained coloured. It is noteworthy that, though these substances deteriorate in air, a sufficient number of molecules survive the film-making process to give a reasonable yield of free radicals.

The use of a thin film allows the formation of free radicals throughout the sample, even by quanta corresponding to wave-lengths where the absorption of the 'Perspex' becomes appreciable (less than about 3,000 A.). These radiations will, however, be able to pass through such a thin film. Furthermore, a thin transparent film should be convenient for optical measurements, and this technique should be useful for studying free radicals which are normally unstable.

We are indebted to the University of Oxford for the award of a Pressed Steel Co., Ltd., research fellowship (D. B.), and to the Department of Scientific and Industrial Research for a maintenance grant (A. C. R.-T.) during the tenure of which these researches were carried out.

D. BIJL

A. C. Rose-Innes

Clarendon Laboratory,

Oxford.

Nov. 6.

${ }^{1}$ Lewis, G. N., et al., J. Amer. Chem. Soc., 64, 2801 (1942); 65, 520, 2419,2424 (1943).

${ }^{2}$ Norman, I., and Porter. G., Nature, 174, 508 (1954).

${ }^{3}$ Bleaney, P.. and Stevens, K. W. H., Reports on Progress in Physics, 16, 109 (1935).

${ }^{4}$ Chu, T. L., Pake, G. E., Panl, D. E., Townsend, J., and Weissman, S. I., J. Phys, Chem., 57, 504 (1953).

\section{Solubility of Oxygen in Water}

IN a recent communication, Truesdale and Downing ${ }^{1}$ reported that the values for the solubility of oxygen in de-ionized distilled water, determined by the Winkler ${ }^{2}$ method, were significantly lower than the standard values commonly employed ${ }^{3}$. They gave a new empirical equation valid in the range $0-40^{\circ} \mathrm{C}$., relating the solubility and the temperature.

In connexion with some investigations on the salting-out of oxygen in aqueous electrolytes, a number of determinations of the solubility of oxygen in distilled water at $25^{\circ} \mathrm{C}$. were made over a period of several months. The Winkler method, modified to the extent that $0.01 \mathrm{~N}$ thiosulphate instead of $0.025 \mathrm{~N}$ usually recommended was employed and, as in the case of the authors mentioned, air freed from carbon dioxide and saturated with water vapour was used. In the experimental arrangement the air was drawn slowly through the water until equilibrium was established.

The results obtained at $25^{\circ} \mathrm{C}$. in five series of determinations gave values, corrected for pressure, in the range $8.07 \pm 0.05$ p.p.m. The equation of Truesdale and Downing yields at $25^{\circ} \mathrm{C}$. a value of 8.11 p.p.m., while the figure quoted in "Standard Methods"3 is 8.38 p.p.m. The present results are an independent confirmation of the results recently reported and underline the need for a revision of the 'standard' values.

$$
\begin{gathered}
\text { Department of Chemistry, } \\
\text { University of Tasmania, } \\
\text { Hobart, Tasmania. } \\
\text { Sept. } 2 .
\end{gathered}
$$

${ }^{1}$ Truesdale, G. A., and Downing, A. L., Nature, 173, 1236 (1954). ${ }^{2}$ Winkler, T. W., Ber. dtsch, chem. Ges., 21, 2843 (1888).

${ }^{3}$ American Public Health Association, "Standard Methods for the Examination of Water and Sewage" 9th edit. (New York, 1946).

\section{Oxygen Exchange between Nitrous Acid and Water}

THE exchange of oxygen atoms between nitrous acid and isotopically enriched water has been followed by the isolation of the nitrous acid as its insoluble silver salt, and the decomposition of this salt, to water, by heating with dry ammonium chloride in vacuo. The water produced was then equilibrated with carbon dioxide, and the isotopic content of this gas determined mass spectrometrically.

The work of Hughes, Ingold and Ridd, and Schmid (summarized in ref. 1), showed that under appropriate conditions the active nitrosating agent in diazotization was dinitrogen trioxide, $\mathrm{N}_{2} \mathrm{O}_{3}$, formed by the reaction :

$$
\mathrm{H}_{2} \mathrm{~N}+\mathrm{O}_{2}+\mathrm{NO}_{-}^{-} \rightleftharpoons \mathrm{N}_{2} \mathrm{O}_{3}+\mathrm{H}_{2} \mathrm{O} \text {; }
$$

but that under somewhat different conditions the reagent was either the nitrous acidium ion, $\mathrm{H}_{2} \mathrm{~N}+\mathrm{O}_{2}$, or the nitrosonium ion, $\mathrm{N}^{+} \mathrm{O}$, derived from it.

Any of these entities, or all, could give oxygen exchange between nitrous acid and water, by reaction (1), by the hydration of the nitrosonium ion (2), or by the reaction between water and the nitrous a.cidium ion $(3)$ :

$$
\begin{aligned}
\mathrm{N}+\mathrm{O}+\mathrm{H}_{2} \mathrm{O} & \rightleftharpoons \mathrm{H}_{2} \mathrm{~N}+\mathrm{O}_{2} \\
\mathrm{H}_{2}{ }^{18} \mathrm{O}+\mathrm{H}_{2} \mathrm{~N}+\mathrm{O}_{2} & \rightleftharpoons \mathrm{H}_{2} \mathrm{~N}+\mathrm{O}^{18} \mathrm{O}+\mathrm{H}_{2} \mathrm{O}
\end{aligned}
$$

A distinction between some of these mechanisms can be made by following the dependence of exchangerate on the concentration of nitrous acid. It can readily be shown that exchange by reaction (1) will follow the kinetic law :

$$
\text { Rate }=k_{2}\left[\mathrm{HNO}_{2}\right]^{2} \text {, }
$$

where $\left[\mathrm{HNO}_{2}\right]$ is the concentration of molecular nitrous acid; but that reactions (2) and (3) will give :

$$
\text { Rate } \propto\left[\mathrm{H}^{+}\right]\left[\mathrm{HNO}_{2}\right] \text {. }
$$

To allow the isolation of sufficient material for our isotopic analysis method, a solution of sodium nitrite (concentration varying between 0.4 and $1 M$ ) was used, and to this was added not more than one-fifth the equivalent of perchloric acid. Under these conditions we can assume the concentration of molecular nitrous acid to be given by the stoichiometric 